\title{
Clinical Study \\ Serum Leptin Levels in Patients with Ocular and Nonocular Behçet's Disease
}

\author{
F. Nilüfer Yalçındağ, ${ }^{1}$ Üçler Kısa, ${ }^{2}$ Figen Batıoğlu, ${ }^{1}$ Ali Yalçındağ, ${ }^{2}$ \\ Özden Özdemir, ${ }^{1}$ and Osman Çağlayan ${ }^{2}$ \\ ${ }^{1}$ Department of Ophthalmology, Faculty of Medicine, Ankara University, 06100 Ankara, Turkey \\ ${ }^{2}$ Department of Clinical Biochemistry, Faculty of Medicine, Kırıkkale University, 71200 Kırıkkale, Turkey
}

Received 9 February 2007; Accepted 13 March 2007

\begin{abstract}
Aims. To investigate serum leptin levels in Behçet's patients with or without ocular involvement compared with healthy subjects and the relationship between serum leptin and uveitis activity in patients with ocular involvement. Methods. Fifty-seven patients with Behçet's disease and 20 healthy control subjects were included in this study. While 27 patients had ocular involvement (18 had acute uveitis, 9 had inactive ocular involvement), 30 did not have ocular disease. C-reactive protein, alpha 1-antitrypsin, and serum leptin levels were measured in all samples. Results. There was a significant difference between the patients with Behçet's disease and control group for both logarithm of leptin $(P=.000)$ and logarithm of CRP $(P=.031)$. Logarithm of leptin in nonocular Behçet's patients was significantly higher compared to its level in ocular Behçet's disease and controls $(P=.009)$. There was a significant difference between the patients with active ocular disease and control group $(P=.03)$. Conclusions. Leptin might have a possible role in the pathogenesis of Behçet's disease.
\end{abstract}

Copyright (๑) 2007 F. Nilüfer Yalçındağ et al. This is an open access article distributed under the Creative Commons Attribution License, which permits unrestricted use, distribution, and reproduction in any medium, provided the original work is properly cited.

\section{INTRODUCTION}

Behçet's disease is a chronic, systemic inflammatory disorder affecting multiple organs with a generalized vasculitis [1]. The etiology and pathogenesis of Behçet's disease have not been entirely enlightened. The main immunological features of Behçet's disease consist of increased T- and B-cell responses to heat-shock proteins, increased neutrophil activity, and alterations in cytokine levels, although the interrelationships between and among these features have not been clarified [2]. Serum levels of neutrophil priming cytokines such as TNF, interleukin- $1 \beta$, and IL- 8 are determined to be raised in patients with Behçet's disease [3].

Leptin is a peptide hormone that regulates body weight as well as endocrine and immune functions [4-6]. Leptin has structural and functional similarities with members of cytokines family [7]. The leptin receptor is homologous to a subunit of the IL-6-type cytokine receptors [8, 9]. Leptin shares the same signal transduction pathway with cytokines [10].

In light of the fact that leptin might participate in the host response to inflammation, we aimed to investigate changes of serum leptin levels in Behçet's patients with or without ocular involvement compared with healthy subjects and the rela- tionship between serum leptin and uveitis activity in patients with ocular involvement. We compared serum leptin changes with other acute phase reactants, such as CRP or alpha-1 antitrypsin ( $\alpha 1$-antitrypsin).

\section{MATERIAL AND METHODS}

Fifty-seven patients with Behçet's disease were included in this study. All patients included in the study met the international diagnostic criteria for Behçet's disease [11]. A complete ophthalmologic examination was performed by ophthalmologists with an interest in Behçet's disease. While 27 patients had ocular involvement, the other 30 did not have ocular disease. All patients with ocular involvement were split into two groups according to the activation of eye involvement to investigate the association between leptin levels and ocular disease activity. Of the 27 patients who had ocular disease, 18 suffered acute uveitis and 9 had inactive ocular involvement at the time of enrollment. None of the Behçet's patients were on systemic steroids or immunosuppressant agents. Twenty healthy control subjects were also included in the study. The subjects who had any systemic or ocular disease were excluded. The subjects were matched for 
TABLE 1: Patient demographics and laboratory findings in patients with ocular and nonocular Behçet's disease and controls.

\begin{tabular}{lcccccc}
\hline & & \multicolumn{3}{c}{ Patients with Behçet's disease (BD) } & & \multirow{2}{*}{ Control subjects } \\
& All BD patients & Nonocular BD & All ocular BD & Active ocular BD & Inactive ocular BD & 9 \\
\hline Number & 57 & 30 & 27 & 18 & 9 & 9 \\
Age (years) & $33.9 \pm 8.1$ & $34.3 \pm 8.9$ & $33.6 \pm 7.5$ & $33.3 \pm 9$ & $34.8 \pm 6.6$ & $34.7 \pm 8.6$ \\
BMI (kg/m $\left.{ }^{2}\right)$ & $25.6 \pm 4.6$ & $25.9 \pm 5.4$ & $25.2 \pm 3.5$ & $26 \pm 3.4$ & $23.7 \pm 3.4$ & $23.8 \pm 3.7$ \\
Log leptin $(\mathrm{ng} / \mathrm{mL})$ & $1.9 \pm 0.4$ & $2 \pm 0.4$ & $1.9 \pm 0.4$ & $1.9 \pm 0.4$ & $1.9 \pm 0.3$ & $1.7 \pm 0.1$ \\
$\alpha 1$-antitrypsin $(\mathrm{mg} / \mathrm{dL})$ & $180.3 \pm 41.7$ & $188.3 \pm 66.3$ & $177.6 \pm 31.2$ & $180.4 \pm 36.8$ & $171.9 \pm 15.7$ & $175.9 \pm 34.3$ \\
Log CRP $(\mathrm{mg} / \mathrm{L})$ & $1.6 \pm 0.6$ & $1.6 \pm 0.6$ & $1.5 \pm 0.7$ & $1.5 \pm 0.7$ & $1.5 \pm 0.8$ & $1.2 \pm 0.5$ \\
\hline
\end{tabular}

age, sex, and body mass index (BMI). Informed consent was obtained from all participants.

A venous blood sample was taken from each patient and control subject between 8.00 a.m. and 10:00 a.m. after an overnight fast. The blood samples were centrifugated to obtain serum. All serum samples were immediately stored at $-80^{\circ} \mathrm{C}$ until use.

C-reactive protein (CRP), $\alpha 1$-antitrypsin, and serum leptin levels were measured in all samples. C-reactive protein and $\alpha 1$-antitrypsin levels were measured by the immunoturbidimetric method using commercial kit (Roche Mannheim, Germany) on P 800 autoanalyzer (Roche). Serum samples were assayed for leptin, using enzyme-amplified sensitivity immunoassay kit (Biosource Europe S.A., Nivelles, Belgium).

Serum leptin levels were compared with those measurings of other acute phase reactants, such as CRP or $\alpha 1$-antitrypsin.

\subsection{Statistics}

Statistical analysis was performed using SPSS 13.0 software for Windows. As the data were not normally distributed, logarithmic values of CRP (log CRP) and leptin (log leptin) levels were used. Statistical analysis was performed by Student $t$ test to compare all Behçet's patients with controls. ANOVA and post hoc test (Tukey HSD) were used to compare ocular Behçet's patients with nonocular Behçet's patients and controls. Kruskal-Wallis and Mann-Whitney $U$ tests were used to compare active ocular Behçet's patients with inactive ocular Behçet's patients, nonocular Behçet's patients, and controls.

Pearson's correlation test was used for evaluating the correlation between different parameters in all groups, apart from the group consisting of the patients with inactive eye involvement. Spearman's correlation analysis was used for evaluating that group. Data were presented as mean \pm SD. A value of $P<.05$ was considered significant.

\section{RESULTS}

Patient characteristics and laboratory findings are outlined in Table 1 . Of the 57 patients in this study, 28 were male $(49.1 \%)$ and 29 were female (50.9\%). There was a significant difference between the patients with Behçet's disease and control group for both log leptin $(P=.000)$ and $\log \mathrm{CRP}(P=.031)$. Log leptin in nonocular Behçet's patients was significantly higher compared to its level in ocular Behçet's disease and controls $(P=.009)$. Log leptin was not different between patients with ocular and nonocular Behçet's disease. However, there was a significant difference between the patients with active ocular Behçet's disease and control group $(P=.03)$.

In patients with Behçet's disease, log leptin was correlated with BMI $(r=.44, P=.001)$, and $\alpha 1$-antitrypsin was correlated with $\log \mathrm{CRP}(r=.61, P=.000)$. On the other hand, there was no significant correlation between log leptin and $\alpha 1$-antitrypsin or log CRP. In patients with nonocular Behçet's disease, $\alpha 1$-antitrypsin was correlated with log CRP $(r=.56, P=.002)$, and log leptin was correlated with BMI $(r=.052, P=.004)$. In patients with ocular Behçet's disease, $\alpha 1$-antitrypsin was correlated with log CRP ( $r=.73, P=.000)$. In patients with active ocular Behçet's disease, $\alpha 1$-antitrypsin was correlated with log CRP $(r=.79$, $P=.000)$. In patients with inactive ocular Behçet's disease, $\log$ leptin was correlated with BMI $(r=.86, P=.007)$, and $\alpha 1$-antitrypsin was correlated with $\log$ CRP $(r=.81$, $P=.014)$. In control group, there was no significant correlation between log leptin and $\alpha 1$-antitrypsin or BMI and log CRP.

\section{DISCUSSION}

Leptin is primarily produced by adipose tissue. Leptin levels in the systemic circulation are controlled by a variety of factors, especially food intakeand the endocrine system [12]. The innate immune system also participates in the regulation of leptin production.

In experimental animals, leptin levels are acutely increased after administration of the inflammatory stimulus such as lipopolysaccharide (LPS) and turpentine, and proinflammatorycytokines such as tumor necrosis factor- $\alpha$ (TNF$\alpha)$ and interleukin-1 (IL-1) $[5,13]$. The kinetics of leptinproduction during infectious and inflammatory processes is similar to that of cytokine induction [14].

Data obtained in human studies regarding the regulation of leptin expression in response to infection and inflammation are varied. The administration of IL- $1 \beta$ or TNF- $\alpha$ results in increased serum leptin levels in healthy subjects $[15,16]$. However, no increase in serum leptin levels was found after LPS injection to humans [17]. Leptin concentrations were found to be elevated during an acute inflammatory stimulus such as major surgery [18]. Nevertheless, in the chronic phase of inflammatory diseases such as rheumatoid arthritis 
and inflammatory bowel disease, inflammation-associated leptin peaks were not observed $[19,20]$.

Although the etiology and pathogenesis of Behçet's disease are not clear, increased serum levels of inflammatory cytokines have been established to correlate with Behçet's disease activity [3-21]. A correlation between leptin levels and disease activity in patients with Behçet's disease has been reported [22]. Leptin levels in 35 patients with Behçet's disease were also found to be higher than in healthy controls in that study [22]. In another study, 28 males with ocular Behçet's disease were compared with 15 healthy controls, and serum levels of leptin were not significantly different between the groups [23]. In that study, leptin levels were compared between patients with ocular Behçet's disease and healthy subjects; whereas, we compared leptin levels between the groups composed of Behçet's patients with and without ocular involvement and healthy subjects. In our study, patients with Behçet's disease with or without ocular involvement were found to have higher serum leptin and CRP levels compared according to age-, sex-, and BMI-matched controls. However, in Behçet's patients with ocular involvement, serum leptin concentrations were not significantly different from those in Behçet's patients without ocular involvement in our study. The results of our study also demonstrated that the mean serum leptin levels were significantly increased in patients with active uveitis compared to control subjects.

Because serum leptin levels are closely associated with the amount of body fat and differ between males and females, BMI- and sex-matched subjects were enrolled in the groups. The subjects were on systemic steroids or immunosuppressive agents were not included in the study to avoid the possible effects of these agents on the serum leptin levels.

In conclusion, the higher serum leptin levels in patients with Behçet's disease compared to control subjects in the present study might be attributed to a possible role for leptin in the pathogenesis of Behçet's disease. Elevated serum leptin level does not seem to be a risk factor in ocular involvement. However, there might be a correlation between leptin levels and uveitis activity. Future studies would be useful to clarify the potential influence of leptin in Behçet's disease.

\section{ACKNOWLEDGMENTS}

We gratefully acknowledge the excellent technical assistance of Fatoş Özyalçın and Emine Uluyüz.

\section{REFERENCES}

[1] R. Rizzi, S. Bruno, and R. Dammacco, "Behçet's disease: an immune-mediated vasculitis involving vessels of all sizes," International Journal of Clinical and Laboratory Research, vol. 27, no. 4, pp. 225-232, 1997.

[2] L. M. Al-Otaibi, S. R. Porter, and T. W. J. Poate, "Behçet's disease: a review," Journal of Dental Research, vol. 84, no. 3, pp. 209-222, 2005.

[3] J.-L. Mege, N. Dilsen, V. Sanguedolce, et al., "Overproduction of monocyte derived tumor necrosis factor $\alpha$, interleukin (IL) 6, IL-8 and increased neutrophil superoxide generation in Behçet's disease. A comparative study with familial Mediter- ranean fever and healthy subjects," Journal of Rheumatology, vol. 20, no. 9, pp. 1544-1549, 1993.

[4] R. S. Ahima and J. S. Flier, "Leptin," Annual Review of Physiology, vol. 62, pp. 413-437, 2000.

[5] G. Fantuzzi and R. Faggioni, "Leptin in the regulation of immunity, inflammation, and hematopoiesis," Journal of Leukocyte Biology, vol. 68, no. 4, pp. 437-446, 2000.

[6] G. Palmer and C. Gabay, "A role for leptin in rheumatic diseases?" Annals of the Rheumatic Diseases, vol. 62, no. 10, pp. 913-915, 2003.

[7] F. Zhang, M. B. Basinski, J. M. Beals, et al., "Crystal structure of the obese protein leptin-E100," Nature, vol. 387, no. 6629, pp. 206-209, 1997.

[8] L. A. Tartaglia, M. Dembski, X. Weng, et al., "Identification and expression cloning of a leptin receptor, OB-R," Cell, vol. 83, no. 7, pp. 1263-1271, 1995.

[9] P. Maruna, R. Gürlich, R. Fraško, and M. Haluzík, “Serum leptin levels in septic men correlate well with C-reactive protein (CRP) and TNF-alpha but not with BMI," Physiological Research, vol. 50, no. 6, pp. 589-594, 2001.

[10] H. Baumann, K. K. Morella, D. W. White, et al., "The full-length leptin receptor has signaling capabilities of interleukin 6-type cytokine receptors," Proceedings of the National Academy of Sciences of the United States of America, vol. 93, no. 16, pp. 8374-8378, 1996.

[11] B. Wechsler, F. Davatchi, Y. Mizushima, et al., "Criteria for diagnosis of Behçet's disease," Lancet, vol. 335, no. 8697, pp. 1078-1080, 1990.

[12] J. M. Friedman and J. L. Halaas, "Leptin and the regulation of body weight in mammals," Nature, vol. 395, no. 6704, pp. 763-770, 1998.

[13] S. Loffreda, S. Q. Yang, H. Z. Lin, et al., "Leptin regulates proinflammatory immune responses," FASEB Journal, vol. 12, no. 1, pp. 57-65, 1998.

[14] P. Sarraf, R. C. Frederich, E. M. Turner, et al., "Multiple cytokines and acute inflammation raise mouse leptin levels: potential role in inflammatory anorexia," Journal of Experimental Medicine, vol. 185, no. 1, pp. 171-175, 1997.

[15] J. E. Janik, B. D. Curti, R. V. Considine, et al., "Interleukin $1 \alpha$ increases serum leptin concentrations in humans," Journal of Clinical Endocrinology and Metabolism, vol. 82, no. 9, pp. 3084-3086, 1997.

[16] M. S. Zumbach, M. W. J. Boehme, P. Wahl, W. Stremmel, R. Ziegler, and P. P. Nawroth, "Tumor necrosis factor increases serum leptin levels in humans," Journal of Clinical Endocrinology and Metabolism, vol. 82, no. 12, pp. 4080-4082, 1997.

[17] S. R. Bornstein, H. L. Preas, G. P. Chrousos, and A. F. Suffredini, "Circulating leptin levels during acute experimental endotoxemia and antiinflammatory therapy in humans," Journal of Infectious Diseases, vol. 178, no. 3, pp. 887-890, 1998.

[18] A. M. Wallace, N. Sattar, and D. C. McMillan, "The coordinated cytokine/hormone response to acute injury incorporates leptin," Cytokine, vol. 12, no. 7, pp. 1042-1045, 2000.

[19] H.-J. Anders, M. Rihl, A. Heufelder, O. Loch, and M. Schattenkirchner, "Leptin serum levels are not correlated with disease activity in patients with rheumatoid arthritis," Metabolism, vol. 48, no. 6, pp. 745-748, 1999.

[20] A. G. Hoppin, L. M. Kaplan, D. Zurakowski, A. M. Leichtner, and A. Bousvaros, "Serum leptin in children and young adults with inflammatory bowel disease," Journal of Pediatric Gastroenterology and Nutrition, vol. 26, no. 5, pp. 500-505, 1998. 
[21] B. Turan, H. Gallati, H. Erdi, A. Gürler, B. A. Michel, and P. M. Villiger, "Systemic levels of the T cell regulatory cytokines IL-10 and IL-12 in Behçet's disease; soluble TNFR-75 as a biological marker of disease activity," Journal of Rheumatology, vol. 24, no. 1, pp. 128-132, 1997.

[22] C. Evereklioglu, H. S. Inalöz, N. Kirtak, et al., "Serum leptin concentration is increased in patients with Behçet's syndrome and is correlated with disease activity," British Journal of Dermatology, vol. 147, no. 2, pp. 331-336, 2002.

[23] S. Kavuncu, F. Koç, M. Kurt, et al., "Evaluation of serum leptin concentration in Behçet's disease with ocular involvement," Graefe's Archive for Clinical and Experimental Ophthalmology, vol. 243, no. 11, pp. 1158-1160, 2005. 


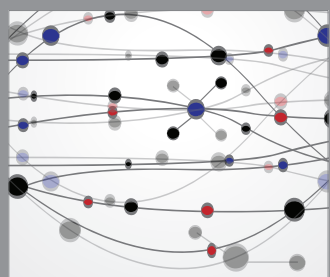

The Scientific World Journal
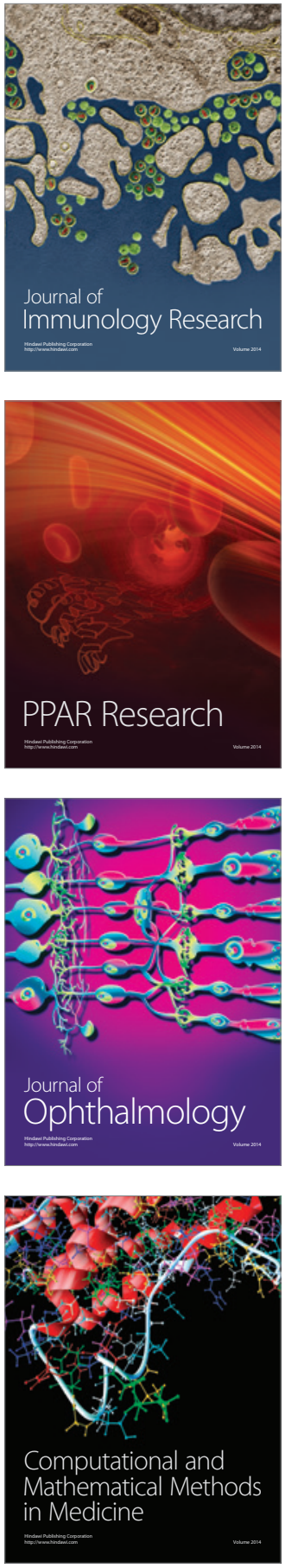

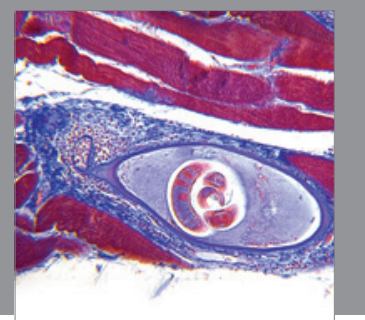

Gastroenterology

Research and Practice
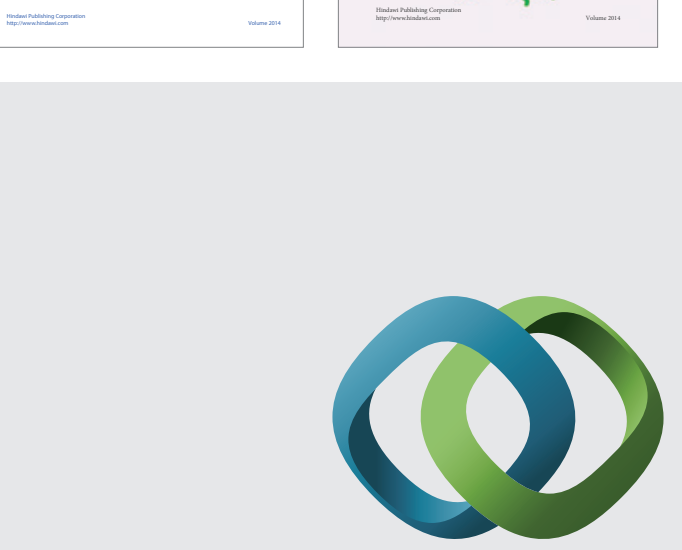

\section{Hindawi}

Submit your manuscripts at

http://www.hindawi.com
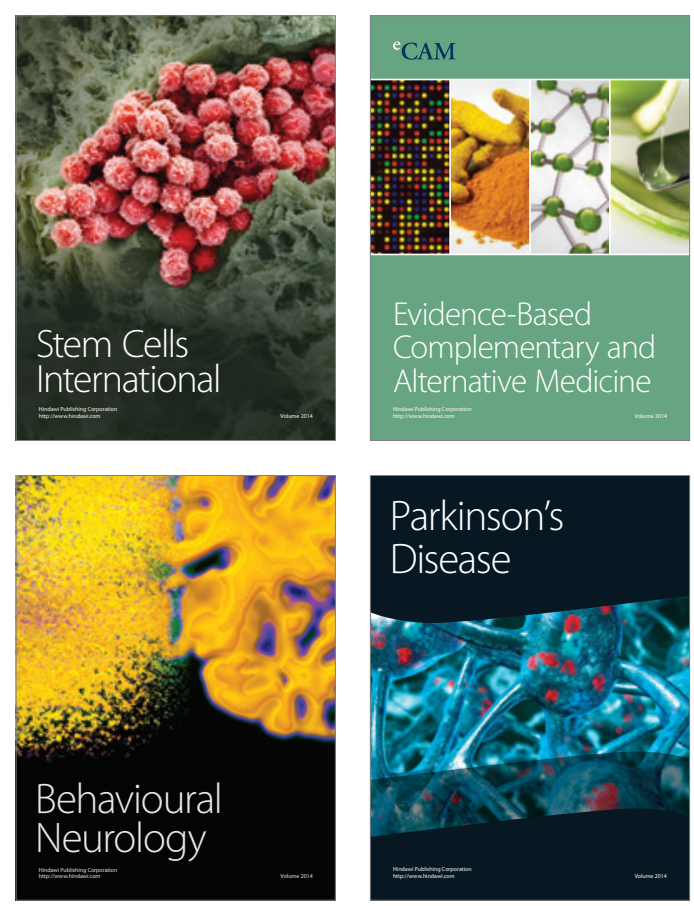

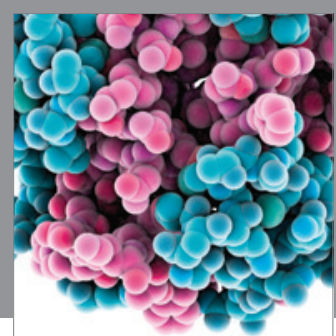

Journal of
Diabetes Research

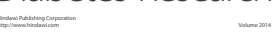

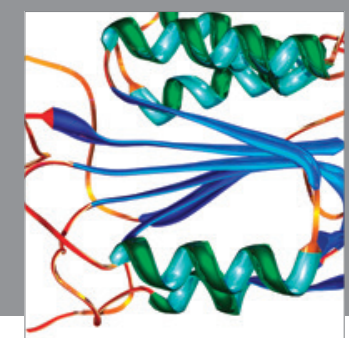

Disease Markers
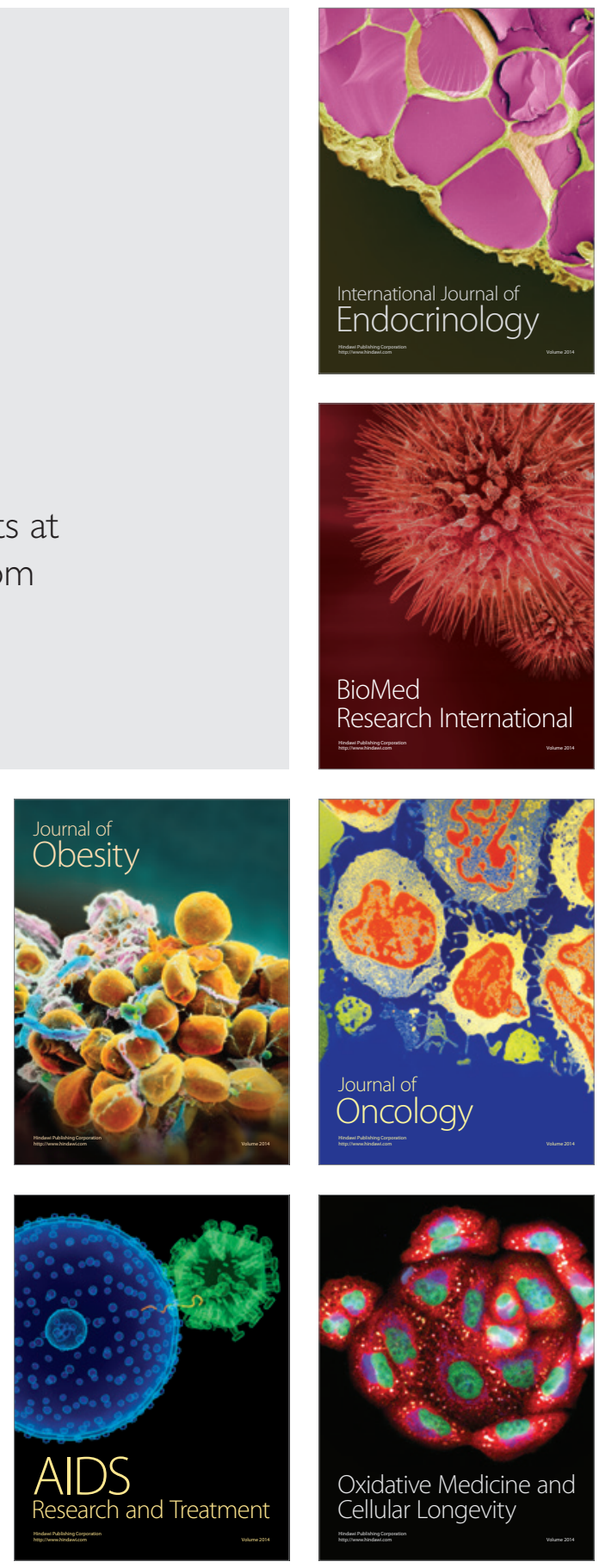